\title{
A instalação da empresa Belagrícola no município de Imbituva- PR e o uso do território
}

\author{
La instalación de la empresa Belagrícola en el municipio de \\ Imbituva-PR y el uso del territorio
}

\section{The installation of Belagricola Company in the City of Imbituva-PR and the Use of Territory}

\author{
Zaqueu Luiz Bobato \\ zaqueudegeo@gmail.com \\ Universidade Estadual do Centro-Oeste / Campus de Irati \\ Robson Christian Barankievicz \\ rcbchristian@hotmail.com \\ Universidade Estadual do Centro-Oeste / Campus de Irati
}

\begin{abstract}
Resumo: Este artigo aborda o conceito de território trazendo reflexões acerca da ideia de 'uso do território'. O debate converge para o caso da lógica econômica de uma empresa nacional denominada Belagrícola. A empresa atua no ramo do agronegócio, e, a partir das reconfigurações propiciadas pelo aparato técnico associado à ciência e a informação, constatou-se que a mesma gera um 'uso consciente' do território no qual se fixou. Desta forma, a partir de trabalhos de campo com entrevistas e questionários, discute-se o caso da empresa e seu uso do território no município de Imbituva, situado na região sudeste do Estado do Paraná.
\end{abstract}

Palavras-chave: Reconfigurações territoriais. Uso do território. Redes de empresas. Agronegócio.

Resumen: Este artículo aborda el concepto de territorio trayendo reflexiones sobre la idea de "uso del territorio". El debate reflexivo converge para el caso de la lógica económica de una empresa nacional llamada "Belagrícola". La empresa opera en el sector del agronegocio, y, a partir de las reconfiguraciones propiciadas por el aparato técnico asociado con la ciencia y la información, se encontró que la misma genera un "uso racional" del territorio en que está establecida. Por lo tanto, este artículo, desde trabajo de campo con realización de entrevistas y aplicación de cuestionario, aborda el caso de la empresa Belagrícola, así como el uso del territorio hecho por ella en el municipio de Imbituva que se encuentra en la región sudeste del Estado de Paraná.

Palabras clave: Reconfiguraciones territoriales. Uso del territorio. Redes de empresas. Agronegocio.

Abstract: This paper covers the concept of territory bringing reflections around the idea of "Use of Territory". The reflexive debate, converge into the case of economical logic of a national company denominated Belagrícola. The company acts in the agribusiness sector, and, from reconfigurations propitiated by the technical device 
associated to science and the information, it was found that the company generates a "conscious use" of the territory in which it settled. Therefore, the present paper made from fieldwork with interviews and questionnaires' applications in order to discuss the Belagrícola's case, as well as the use of territory made by it at the city of Imbituva that is located on the southeast of Parana's State.

Keywords: Territorial reconfiguration. Use of Territory. Companies networks. Agribusiness.

\section{INTRODUÇÃO}

O meio 'técnico-científico-informacional' associado à intensificação da dinâmica capitalista tem gerado reconfigurações em diversos espaços territoriais, sendo que tais reconfigurações ocorrem na esfera da cultura da política da economia do meio ambiente (SANTOS, 1996). No caso da atuação das empresas, sobretudo as de grande porte, estas muitas vezes utilizam dos recursos naturais, técnicos, econômicos, culturais e sociais de um dado território, a fim de usá-los a seu favor. Destaca-se que em meio a essa compreensão sobre o uso do território, esta pesquisa procura compreender a lógica econômica de uma empresa nacional que atua no ramo do agronegócio, e que a partir das reconfigurações propiciadas pelo aparato técnico associado à ciência e a informação, gera um uso consciente do território no qual se está fixada.

Portanto, este artigo inicia refletindo o conceito de território, em seguida, aborda o debate acerca do uso do território. Faz-se necessário enfocar, mesmo que brevemente, a discussão acerca da forma de organização em redes, já que muitas empresas operam no território apropriando-se de redes e, ao mesmo tempo, formando redes, fato que permite um uso territorial mais intenso.

Na sequência faz-se um resgate histórico da origem da empresa Belagrícola e sua construção no município de Imbituva. Explicitam-se os dados obtidos na pesquisa de campo realizada com o responsável pela empresa no município bem como com a população do entorno. Ressaltar-se-á por meio das constatações a estratégia de uso do território pela empresa, como também o impacto socioeconômico gerado por ela no território, e as opiniões das pessoas moradoras nas comunidades vizinhas às suas instalações.

\section{O USO DO TERRITÓRIO E AS REDES GEOGRÁFICAS}

O conceito de território na Geografia enquanto ciência institucionalizada (pós o século XIX) emerge a partir das análises estabelecidas pelo geógrafo alemão Ratzel. Para Ratzel o 'espaço vital' era a base para a vida do homem. Ele considerava que a partir do momento em que o 'espaço vital' não mais possibilitasse a manutenção da vida de um grupo social, haveria assim a necessidade de expansão, pois, na medida em que o homem alcançasse os limites do seu espaço, o que o tornaria insuficiente para a sua sobrevivência, tornava-se necessário o mesmo conquistar novos 'espaços'. Desta maneira, territorializar 
novos espaços era algo imprescindível, assim como protegê-lo (MORAES, 1996). Ressaltase que é com Ratzel que se tem uma discussão mais acalorada sobre o conceito, e, a partir desse geógrafo, vários outros passaram a abordar o conceito.

Evidencia-se que é importante ter a compreensão de que os estudos que vão abordando o território pós-século XIX, devido às filiações teóricas e filosóficas a que se pautam, em muitos momentos se caracterizam divergentes no que diz respeito ao processo que os formam. Nas palavras de Haesbaert (2011, p. 45) pensar o território depende “[...], da posição filosófica a que estiver filiado o pesquisador". Assim sendo, é lúcido conceber que sobre a perspectiva do território alguns priorizam fatores econômicos, outros culturais ou políticos, ou ainda naturais, assim como a junção de fatores, o que é característico da perspectiva integradora. No entanto, é consenso de que relações de poder confluem para que haja uma formação territorial.

Raffestin (1993) em sua construção conceitual entende o território como sendo decorrente de uma apropriação do espaço. Em suas palavras:

É essencial compreender bem que o espaço é anterior ao território. O território se forma a partir do espaço, é o resultado de uma ação conduzida por um ator sintagmático (ator que realiza um programa) em qualquer nível. Ao se apropriar de um espaço, concreta ou abstratamente [...] o ator territorializa o espaço (RAFFESTIN, 1993, p. 143).

Raffestin (1993) se refere ao território destacando que ele é marcado pelas relações de poder, pois, poder e território vão ser enfocados em conjunto para a compreensão do conceito, mesmo existindo a autonomia de cada um. Nas palavras do autor:

[...] um espaço onde se projetou um trabalho, seja energia e informação, e que, por conseqüência, revela relações marcadas pelo poder. (...) o território se apoia no espaço, mas não é o espaço. É uma produção a partir do espaço. Ora, a produção, por causa de todas as relações que envolvem, se inscreve num campo de poder [...] (RAFFESTIN, 1993, p. 144).

Seguindo o pensamento de Raffestin, Saquet (2003) considera que a ideia de poder se torna uma constante para a discussão do conceito de território. Nas palavras de Saquet (2003, p. 10) o território é:

Produzido espaço-temporalmente pelas relações de poder engendradas por um determinado grupo social. Dessa forma, pode ser temporário ou permanente e se efetiva em diferentes escalas, portanto, não apenas naquela convencionalmente conhecida como o 'território nacional' sob gestão do Estado-Nação.

Como se pode notar, as bases centrais das discussões que procuram entender o conceito de território estão ligadas às questões de poder, questões essas que tornam possível a diferenciação do que se entende sobre espaço e o que seria o território propriamente dito. Nas palavras de Andrade (1995) constata-se que: 
O conceito de território não deve ser confundido com o de espaço [...] o território está associado à ideia de poder, de controle, quer se faça referência ao poder público, estatal, quer ao poder das grandes empresas que estendem os seus tentáculos por grandes áreas territoriais, ignorando as fronteiras políticas (ANDRADE 1995, p. 19).

Já Haesbaert (2011), ao abordar em seus escritos a discussão sobre território, esclarece que no decorrer dos tempos se desenhou pelos menos duas vertentes interpretativas que muitas vezes se opuseram, sendo elas: a naturalista, e a etnocêntrica. De acordo com Haesbaert (2011, p. 118) a concepção dita naturalista:

[...] vê o território num sentido físico, material, como algo inerente ao próprio homem, quase como se ele fosse uma continuidade do seu ser, como se o homem tivesse uma raiz na terra - o que seria justificado, sobretudo, pela necessidade do território, de seus recursos, para a sua sobrevivência biológica.

Essa perspectiva advém do pensamento ratzeliano que o relacionava ao solo, às condições físico-naturais, sendo que o território poderia propiciar, ou, condicionar o desenvolvimento de uma determinada coletividade, daí a necessidade de sua constante expansão. Já a concepção etnocêntrica abordada pelo autor, “ignora toda relação sociedade-natureza, como se o território pudesse mesmo prescindir de toda base natural (e, mais ainda, sagrada) e fosse uma construção puramente humana, social (HAESBAERT 2011, p. 119)".

Na visão tida como etnocêntrica, as relações sociais são destacadas como exclusivas na formação de um território, descartando os resultantes das interações travadas entre os agentes humanos e a natureza. Contudo, o próprio Haesbaert (2011) aponta que tais relações jamais podem ser vistas de forma isolada, ambas se fazem presentes na sua formação. Resumindo, Haesbaert (2011, p. 121) afirma que “[...] o território é o produto de uma relação desigual de forças, envolvendo o domínio ou controle político-econômico do espaço e sua apropriação simbólica, ora conjugados e mutuamente reforçados, ora desconectados e contraditoriamente articulados".

Compreende-se que para Haesbaert os resultantes das relações de poder também se fazem presentes na constituição de um território, e, dependendo do contexto do poder, seja ele político, econômico, social, familiar, tecnológico que envolve as diferentes escalas geográficas, fato característico do mundo contemporâneo, tem-se o surgimento de múltiplos territórios, por conseguinte, têm-se personificações de poder diferenciadas. Os múltiplos territórios na visão do autor, podem se articular através das redes materiais e imateriais que compõe o espaço geográfico.

Haesbaert (2011) também aponta a relação sociedadade-natureza na concretude do território, pois a ideia do autor de múltiplos territórios interligados por redes, que se caracterizam sendo frutos da expansão dos mecanismos técnicos científicos próprios do sistema capitalista, pressupõem uma trama de relações que envolvem a sociedade e a natureza que foi sendo construída no decorrer do processo de produção do espaço, logo, de territórios, permitindo existir na atualidade o complexo sistema territorial múltiplo. 
Também cumpre destacar que Santos (2006, p.13) ao fazer análises sobre o território, enfatiza que ele "[...] é o lugar em que desembocam todas as ações, todas as paixões, todos os poderes, todas as forças, todas as fraquezas, isto é, onde a história do homem plenamente se realiza a partir das manifestações da sua existência". Percebe-se que para Milton Santos o território abarca uma gama variada de elementos, sobretudo, referentes a aspectos sociais. Todavia, a relação sociedade-natureza apesar de não ser muito enfatizada por ele, comparece, pois:

O território não é apenas o conjunto dos sistemas naturais e de sistemas de coisas superpostas; o território tem que ser entendido como o território usado, não o território em si. O território usado é o chão mais a identidade. A identidade é o sentimento de pertencer àquilo que nos pertence. $\mathrm{O}$ território é o fundamento do trabalho; o lugar da residência, das trocas materiais e espirituais e do exercício da vida. O território em si não é uma categoria de análise em disciplinas históricas, como a geografia. É o território usado que é uma categoria de análise (SANTOS 2006, p. 14. Grifo nosso).

Para o autor a construção de um território dá-se pelo seu uso, ora, a ideia de usar traz embutida em si uma relação de mutuação entre sociedade e natureza, portanto, é a partir desta lógica de relação que o território passa a ser usado. Santos e Silveira (2012) estabelecem que:

Por território entende-se geralmente a extensão apropriada e usada. Mas o sentido da palavra territorialidade como sinônimo de pertencer àquilo que nos pertence... esse sentimento de exclusividade e limite ultrapassa a raça humana e prescinde da existência de Estado. Assim, essa ideia de territorialidade se estende aos próprios animais, como sinônimo de área de vivência e de reprodução. Mas a territorialidade humana pressupõe também a preocupação como o destino, a construção do futuro, o que, entre os seres vivos, é privilégio do homem (SANTOS; SILVEIRA 2012, p. 19).

No que tange ao uso do território, Santos e Silveira (2012) destacam que este se define pela implantação de infraestruturas, bem como, pelo dinamismo da economia e da sociedade. Sendo assim, o poder está implícito nas ações que perpassam a construção de territórios. Nas palavras de Santos e Silveira (2012, p. 21), o uso do território pode ser definido pela:

[...] implantação de infraestruturas, para as quais estamos igualmente utilizando a denominação 'sistemas de engenharia', mas também pelo dinamismo da economia e da sociedade. São os movimentos da população, a distribuição da agricultura, da indústria e dos serviços, o arcabouço normativo, incluídas a legislação civil, fiscal e financeira, que, juntamente com o alcance e a extensão da cidadania, configuram as funções do novo espaço geográfico.

A partir dos autores acima, compreende-se que o uso do território se fundamenta na implantação de infraestruturas que possibilitam fluxos contínuos de matérias, sendo esse ponto abordado por Santos e Silveira (2012) como um 'sistema de engenharia'. 
Santos e Silveira (2012) destacam que o grande momento modelador do território brasileiro ocorreu após a Segunda Guerra Mundial, pois foi nesse momento que se tornou possível notar que a ausência de uma rede nacional de transporte em um país de proporções continentais causava enormes dificuldades. A partir de então, foi necessário equipar o território de acordo com os recursos modernos, visando assim a sua fluidez, pois, a partir do período pós-guerra surgiu uma nova divisão do trabalho no Brasil.

Essa modernização imposta ao território brasileiro desde o pós-guerra exigiu a produção e instalação não apenas de uma tecnoesfera - obras de engenharia e sistemas técnicos que substituem o meio natural ou o meio técnico pré-existente, mas também de uma psicoesfera que adaptasse o território aos projetos pré-concebidos de urbanização, industrialização e modernização agrícola (SANTOS, 1996), logo, um uso acirrado e competitivo passou a ocorrer no Brasil.

\section{A TERRITORIALIZAÇÃO DE EMPRESAS EM REDES}

De modo a estabelecer um entendimento sucinto para a rede geográfica torna-se necessário conhecer a origem do termo 'rede'. Elucida-se que o elemento humano já nos tempos primórdios por meio do uso de técnicas e ações desenvolvidas nos espaços que territorializava, já produzia organizações em formas de rede. Segundo Musso (2004, apud COSTA; UEDA 2007), a noção de rede não é recente, remete à Antiguidade Clássica, quando estava ligada ao labirinto. Este representaria uma reticulação espacial, a partir das linhas e pontos de conexão que permitiriam passagem.

Em Costa (2008) encontram-se exemplos de organizações em redes, onde de acordo com ele os povos egípcios na antiguidade desenvolveram grandes canais de irrigação para as necessidades agrícolas da época. Também os romanos criaram meios de suprir suas demandas territoriais por meio da construção de estradas que atravessavam todo o seu Império, podendo assim obter um maior controle sobre a circulação dos fluxos que ali ocorriam. Portanto, é a partir desse levantamento histórico que se compreende as incipientes organizações em redes, pois as formas de linhas e pontos de conexão geradas por labirintos, por canais de irrigação, bem como por estradas, passaram a redesenhar o território na forma de redes.

No contexto histórico e geográfico da Idade Média, o processo de tecelagem passou a ser associado às redes, já que o entrelaçamento dos fios do tecido formava um emaranhado reticulado (MUSSO, 2004 apud COSTA; UEDA, 2007). Nas palavras de Costa e Ueda (2007, p. 134) o uso do termo empregado à atividade da tecelagem "influenciou a medicina da Idade Moderna, passando a ser utilizado associado ao organismo, simbolizando a circulação, passagem de fluxo no corpo humano, no qual o sangue era a principal representação". Contudo, até fins do século XVIII, a rede era uma questão de metáfora do labirinto, do corpo humano, ou seja, ainda não havia uma materialidade técnica da mesma. De acordo com Costa e Ueda (2007), é somente a partir do período de século XVIII, 
principalmente com a expansão do capitalismo na Europa, que a rede se torna um artefato material incorporado ao espaço.

Em Costa e Ueda (2007), compreende-se que no século XVIII com Saint - Simon começou-se a se pensar a relação de território e redes de uma forma materializada (infraestruturas) e imaterializada (informações). Nas palavras dos autores:

[...] essa emergência capitalista pode ser observada na Filosofia de Saint Simon que passa a defender a difusão das redes como uma condição de desenvolvimento. O discurso do Conde de Saint Simon defendia a proposta de que a construção de redes técnicas seria uma forma de promover o desenvolvimento da indústria e dos transportes e, assim, possibilitar uma melhoria da qualidade de vida da população. Porém, não é necessariamente ele, mas seus discípulos, os grandes responsáveis pelo que Musso (2004) chama de ideologia das redes. Segundo o autor, os discípulos de Saint-Simon, em especial, Michel Chevalier, passaram a propagar a idéia de redes como sinônimo de desenvolvimento. (COSTA; UEDA 2007, p. 134).

Compreende-se que a partir da noção de entrelaçamento, malha e estrutura reticulada, a palavra rede foi ganhando significados ao longo dos tempos, se intensificando a partir da consolidação do sistema capitalista. Em tempo recente o processo de redes é entendido como:

Um conjunto de localizações geográficas interconectadas entre si por um certo número de ligações. Este conjunto pode ser constituído tanto por uma sede de cooperativa de produtores rurais e as fazendas a ela associadas como pelas ligações materiais e imateriais que conectam a sede de uma grande empresa, seu centro de pesquisa e desenvolvimento, suas fábricas, depósitos e filiais de venda (CORRÊA, 2001, p. 107).

Ainda nas palavras de Corrêa (2001, p. 109):

As redes geográficas são, como qualquer materialidade social, produtos e condições sociais. Na fase atual do capitalismo a importância das diversas redes geográficas na vida econômica, social, política e cultural é enorme e, de um modo ou de outro, todos estamos inseridos em mais de uma rede geográfica e, simultaneamente, excluídos ou ausentes de um número ainda maior de redes.

Compreende-se que quando as redes técnicas se implantam materialmente em um território, não é aleatoriamente que isso se faz. A rede traz em si uma função que é atribuída pelo conjunto de ações que a implanta. Assim sendo, entende-se que a função da rede é interligar os pontos de fluxos, tornando-se um instrumento de ação para os atores que atuam no território. Desta maneira, acredita-se que a instalação de empresas em diferentes territórios, muitas vezes em áreas remotas, somente se torna possível a partir de um sistema de atuação baseada em diferentes tipos de redes: as de infraestrutura que compreendem as redes de transporte; as de comunicações e informações; e as de serviços que são representadas pelas redes informacionais (PEREIRA; KAHIL, 2006).

Santos e Silveira (2012) salientam que o aprimoramento das redes de transporte e de comunicações possibilitou uma evolução e melhor fluidez do território, em suas palavras: 
Ampliam-se as redes de transportes, que se tornam mais densas e mais modernas; e graças a modernização das comunicações, criam-se condições de fluidez do território, uma fluidez potencial, representada pela presença de infraestruturas, e uma fluidez efetiva significada pelo uso do solo (SANTOS; SILVEIRA, 2012, p. 49).

Levando em consideração o pensamento dos autores acima citados, entende-se que para a lógica territorial das grandes empresas, os processos de intensificação das redes materiais e imateriais se caracterizam de grande importância, pois conferem a elas fluidez e rentabilidade. As empresas se fixam em determinado local com base na sua lógica territorial, com isso buscando a melhor opção de localização no espaço, fato que favorece a expansão de suas atividades.

\section{ASPECTOS TERRITORIAIS E USO ESTRATÉGICO}

Santos e Silveira (2012) ressaltam que quando se fala em ordem espacial, estar-se-á se referindo ao espaço explicado pelo seu uso. Nas palavras dos autores, "cada momento da história tende a produzir sua ordem espacial, que se associa a uma ordem econômica e a uma ordem social. É necessário entender sua realidade a partir de forças que, frequentemente, não são visíveis a olho nu" (SANTOS; SILVEIRA 2012, p. 289). Os autores permitem compreender que em diferentes contextos históricos e geográficos a organização de espaços territoriais se manifesta a partir das formas econômicas e sociais existentes no momento, logo, as ações provenientes da estruturação política e técnica também se fazem presentes.

No caso do Brasil, quando se estuda a organização de seus espaços territoriais, percebe-se que a partir dos anos 1990 o processo de globalização passou a se intensificar gerando reconfigurações, as quais dizem respeito às mudanças nas formas de organização das empresas, da produção agrícola, dos sistemas de transporte entre outros (SANTOS; SILVEIRA, 2012). Destaca-se que o avanço do meio técnico-científico-informacional, ou seja, a associação entre técnica, ciência e informação, foram fatores importantes para tais reconfigurações.

Ora, a intensificação das organizações em redes se beneficia dos fatores acima descritos, sendo que tais lógicas reticulares passaram a ser apropriadas pelas grandes empresas, permitindo-as estabelecerem um 'uso consciente do território'. De acordo com Santos e Silveira (2012, p. 290) "cada empresa, cada atividade necessita de pontos e áreas que constituem a base territorial de sua existência, como dados da produção e da circulação e do consumo [...]". As redes de transportes, incluindo a materialidade de infraestrutura das mesmas, são elementos importantes para a seleção das áreas de atuação das empresas. Segundo os autores:

Cada empresa, cada ramo da produção produz, paralelamente, uma lógica territorial. [...], esta é visível por meio do que se pode considerar uma topologia, isto é, a distribuição no território dos pontos de interesse para a operação dessa empresa. Esses pontos de interesse ultrapassam o âmbito da própria firma para se projetar sobre as empresas fornecedoras, ou compradoras, ou distribuidoras. Para cada uma delas, o 
território do seu interesse imediato é formado pelo conjunto dos pontos essenciais ao exercício de sua atividade, nos seus aspectos mais fortes. (SANTOS; SILVEIRA 2012, p. 292).

Acredita-se que a presença de uma grande empresa, seja de atuação escalar global, nacional ou regional, leva em consideração a estrutura de consumo, as infraestruturas materiais e sociais existentes, ou que serão possibilitadas por um dado território. Chama a atenção que:

As empresas mais poderosas escolhem os pontos que consideram instrumentais para a sua existência produtiva. É uma modalidade de exercício do seu poder. O resto do território torna-se, então, o espaço deixado às empresas menos poderosas. Os primeiros seriam, do ponto de vista da produtividade, da competitividade, 'espaços luminosos', enquanto o resto do território chamar-se-ia 'espaços opacos'. Na verdade, as coisas não se dão de maneira tão simples. Em primeiro lugar, os pontos luminosos abrigam também as atividades menos luminosas, que tanto podem ser complementares às atividades mais dinâmicas como resultar da permanência, em cada lugar, de uma sociedade desigualitária. Em segundo lugar, o que existe é toda uma gama de lugares luminosos e de lugares opacos, disputados por empresas com diferentes graus de modernidade capitalista ou organizacional (SANTOS; SILVEIRA 2012, p. 294).

Mediante essas discussões, compreende-se que o poder de uso do território ocorre de forma diferenciada a partir da condição de importância das empresas, no entanto, as condições materiais de um dado território se caracterizam importantes para que as empresas deles se apropriem. Desta forma, é a partir do debate que foi estabelecido até aqui que se procurará evidenciar o caso da instalação da empresa Belagrícola no território imbituvense.

\section{CARACTERIZAÇÃO DO TERRITÓRIO MUNICIPAL DE IMBITUVA-PR}

O território municipal de Imbituva encontra-se localizado na Mesorregião Sudeste Paranaense - distante a $76 \mathrm{~km}$ de Ponta Grossa (polo regional) e a $181 \mathrm{~km}$ de Curitiba (capital do Estado), mais especificadamente na Microrregião geográfica de Prudentópolis (IPARDES, 2006). No que tange ao clima, este se caracteriza por um clima subtropical úmido mesotérmico, com verões frescos e invernos rigorosos, sem estação seca. As altitudes médias no município estão em torno de 890 metros (MINEROPAR, 2002).

De acordo com dados do IBGE (2010), o município de Imbituva, com uma área de aproximadamente $736,536 \mathrm{~km}^{2}$, possui 28.455 habitantes, sendo 10.567 residentes na zona rural e 18.888 na zona urbana, com densidade demográfica de 37,61 hab./ km².

O município está localizado em um importante entroncamento rodoviário do Estado, formado por três rodovias - BR 373, BR 153 e PR 522 - que lhe conferem vantagens logísticas. No que diz respeito à economia do território municipal, o ramo madeireiro, de calçados e, por último, o de malhas de tricô, contribuem no processo de geração de empregos e renda no município (IBGE, 2013b; IPARDES, 2013; PREFEITURA, 2013). Entretanto, em 
geral é "a agricultura que responde pela grande parte do Produto Interno Bruto (PIB) do município, tendo como principais destaques os produtos agrícolas: fumo, soja, milho, feijão" (PREFEITURA, 2013).

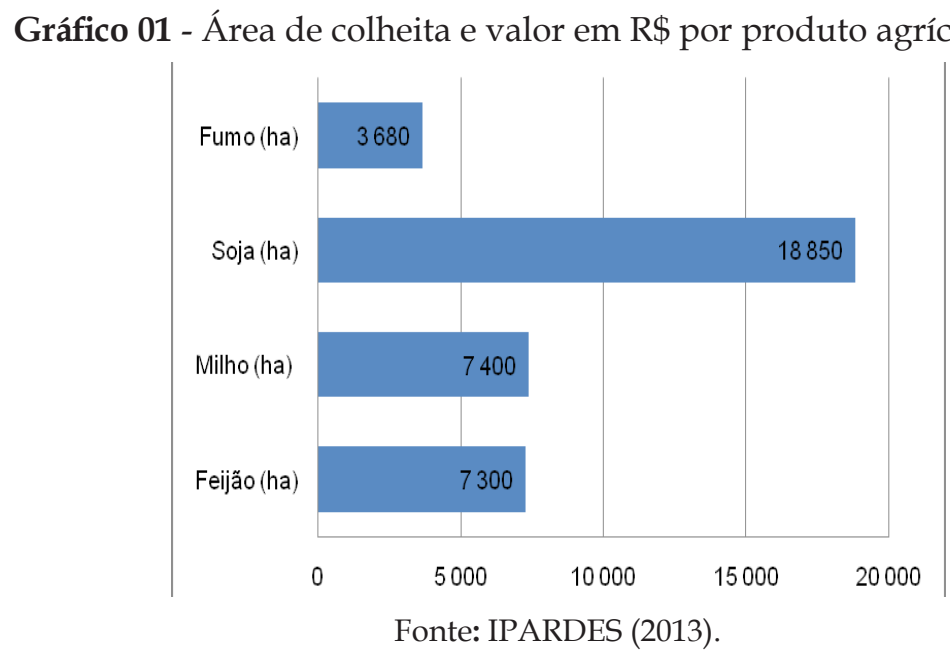

No gráfico 01 é possível visualizar o impacto da agricultura no território imbituvense. Os dados evidenciam que a agricultura do município tem o cultivo do soja ocupando maiores quantidades de terras em hectare, seguida por milho, feijão e fumo. Embora a lavoura de fumo ocupe a menor área no território, possui alto valor agregado e torna-se uma alternativa ao produtor com menos de 20ha disponíveis ao plantio, quando o soja torna-se mais rentável ao produtor.

Ao ser constatada a significância das atividades ligadas à agricultura no município, os dados que apontam para o número de estabelecimentos caracterizados como agricultura 'familiar e 'não familiar' (Quadro 01) permitem compreender que 78\% (1.632 estabelecimentos) possuem até 20 ha e apenas 22\% (448 estabelecimentos) são maiores de 20ha. No caso dos agricultores que possuem pequenas propriedades, estes cultivam fumo em larga escala, já que tal produto permite boa rentabilidade mesmo dispondo de pouca terra, diferente no caso do soja, milho e feijão (BOBATO, 2013).

Quadro 01 - Grupos de área total, segundo indicadores da agricultura familiar e não familiar - FAO.

Município de Imbituva-PR, ano 2006

\begin{tabular}{|l|l|l|}
\hline \multirow{2}{*}{ Grupos de área total } & $\begin{array}{l}\text { Número de estabelecimentos } \\
\text { agropecuários com agricultura } \\
\text { familiar (Unidades) }\end{array}$ & $\begin{array}{l}\text { Número de estabelecimentos } \\
\text { agropecuários com agricultura não } \\
\text { familiar (Unidades) }\end{array}$ \\
\hline Menos de 2 ha & 345 & 16 \\
\hline 2 a menos de 5 ha & 520 & 25 \\
\hline 5 a menos de 10 ha & 386 & 16 \\
\hline 10 a menos de 20 ha & 301 & 23 \\
\hline 20 a menos de 50 ha & 250 & 17 \\
\hline 50 a menos de 100 ha & 79 & 20 \\
\hline 100 ha e mais & 33 & 49 \\
\hline
\end{tabular}

Fonte: IBGE. Disponível em: <http:/ / www.sidra.ibge.gov.br> 


\section{A EMPRESA BELAGRÍCOLA E SUA INSTALAÇÃO NO MUNICÍPIO DE IMBITUVA-PR}

A empresa Belagrícola começou a atuar no mercado agrícola no ano de 1985 no município de Bela Vista do Paraíso, localizado na Mesorregião do Norte Central Paranaense, na Microrregião geográfica de Porecatu (IPARDES, 2012). No início a empresa era apenas representante de vendas de adubos no município de Bela Vista do Paraíso mas passados dois anos, em 1987, o nome Belagrícola se fortaleceu e passou a expandir seus negócios comercializando além de adubos, defensivos e sementes. No ano de 1999 a Belagrícola havia se expandido para um número de 21 filiais. No ano de 2001 a empresa direcionou investimentos para a sua primeira unidade de recebimentos de grãos no município de Bela Vista do Paraíso. Em 2013 a área de atuação da empresa abrangia 1.000.000 hectares na Região Norte do Paraná e Sudoeste do Estado de São Paulo, totalizando mais de 6.000 clientes (Quadros 02 e 03).

Quadro 02 - Lojas de insumos e produtos agrícolas da empresa Belagrícola em 2013

\begin{tabular}{|l|l|l|l|}
\hline MUNICÍPIO & ESTADO & MUNICÍPIO & ESTADO \\
\hline Alvorada do Sul & Paraná & Ivaí & Paraná \\
\hline Aquidaban & Paraná & Londrina & Paraná \\
\hline Arapongas & Paraná & Lupionópolis & Paraná \\
\hline Assaí & Paraná & Nantes & São Paulo \\
\hline Assis & São Paulo & Palmeira & Paraná \\
\hline Astorga & Paraná & Palmital & São Paulo \\
\hline Bela Vista do Paraíso & Paraná & Pitangueiras & Paraná \\
\hline Caixa De São Pedro & Paraná & Ponta Grossa & Paraná \\
\hline Cambé & Paraná & Primeiro de Maio & Paraná \\
\hline Cândido Mota & São Paulo & Rolândia & Paraná \\
\hline Cornélio Procópio & Paraná & Sabáudia & Paraná \\
\hline Correia de Freitas & Paraná & Santa Cecília do Pavão & Paraná \\
\hline Cruzália & São Paulo & Santa Mariana & Paraná \\
\hline Ibiporã & Paraná & Sertaneja & Paraná \\
\hline Ibirarema & São Paulo & Sertanópolis & Paraná \\
\hline Imbituva & Paraná & Tamarana & Paraná \\
\hline Ipiranga & Paraná & Teixeira Soares & Paraná \\
\hline Irerê & Paraná & Tibagi & Paraná \\
\hline
\end{tabular}

Fonte: <http:/ / www.belagricola.com.br>. 
Quadro 03 - Municípios que possuem unidades de recebimento e comercialização de grãos da empresa Belagrícola em 2014

\begin{tabular}{|l|l|l|l|}
\hline MUNICÍPIO & ESTADO & MUNICÍPIO & ESTADO \\
\hline Alvorada do Sul & Paraná & Irerê & Paraná \\
\hline Aquidaban & Paraná & Ivaí & Paraná \\
\hline Aricanduva (Arapongas) & Paraná & Lupionópolis & Paraná \\
\hline Assaí & Paraná & Nantes & São Paulo \\
\hline Assis & São Paulo & Palmital & São Paulo \\
\hline Astorga & Paraná & Prado Ferreira & Paraná \\
\hline Bela Vista do Paraíso & Paraná & Primeiro de Maio I & Paraná \\
\hline Caixa De São Pedro & Paraná & Primeiro de Maio II & Paraná \\
\hline Cambé & Paraná & Sabáudia & Paraná \\
\hline Cândido Mota & São Paulo & Santa Cecília do Pavão & Paraná \\
\hline Correia de Freitas & Paraná & Santa Mariana & Paraná \\
\hline Cruzália & São Paulo & Sertaneja & Paraná \\
\hline Ibiporã & Paraná & Sertanópolis & Paraná \\
\hline Ibirarema & São Paulo & Sertanópolis II & Paraná \\
\hline Iepê & São Paulo & Tamarana & Paraná \\
\hline Imbituva & Paraná & Teixeira Soares & Paraná \\
\hline
\end{tabular}

Fonte: <http://www.belagricola.com.br>.

Como já abordado, a organização em redes possibilita uma melhor articulação, sobretudo para as empresas que dispõem de capital financeiro. A partir da lógica organizacional reticulada, estas conseguem estabelecer uma melhor topologia, ou seja, pontos de interesses para atuação, desta maneira, intensificando o uso do território (SANTOS; SILVEIRA, 2012). A empresa Belagrícola forma uma rede na medida em que amplia sua área de atuação dentro e fora do Estado do Paraná. Além da atuação em rede, a empresa também utiliza das materialidades reticulares, como por exemplo, das infraestruturas dos sistemas de transportes rodoviários, ferroviários, pois as localizações das unidades de compra e venda se situam estrategicamente localizadas próximas a este tipo de rede para que o escoamento seja facilitado.

Em pesquisas no site ${ }^{1}$ da empresa encontram-se que:

A Belagrícola atua diretamente no campo como provedora de soluções, participando ativamente nas decisões do produtor em todas as etapas da agricultura: Preparo de solo e plantio; Monitoramento da lavoura, fornecimento e aplicação de insumos de alta tecnologia; Colheita, armazenagem e comercialização de safra (BELAGRICOLA,2013).

1 BELAGRICOLA. Nossa empresa. 2013. Disponível em: <http://www.belagricola.com.br/nossa-empresa/quem-somos>. Acesso em 10 out. 2013. 
A empresa faz a compra de grãos, presta assistência técnica especializada ao produtor, vende insumos agrícolas, comercializa produtos e realiza financiamento de safra para os agricultores que a ela recorrem.

No município de Imbituva a empresa iniciou a construção de uma unidade de recebimento e comercialização de grãos no início do ano de 2013, na área que compreende a divisa territorial de duas comunidades da zona rural - Valinhos e Mato Branco de Baixo (Fig. 01).

Figura 01 - Situando a empresa Belagrícola no território de Imbituva-PR

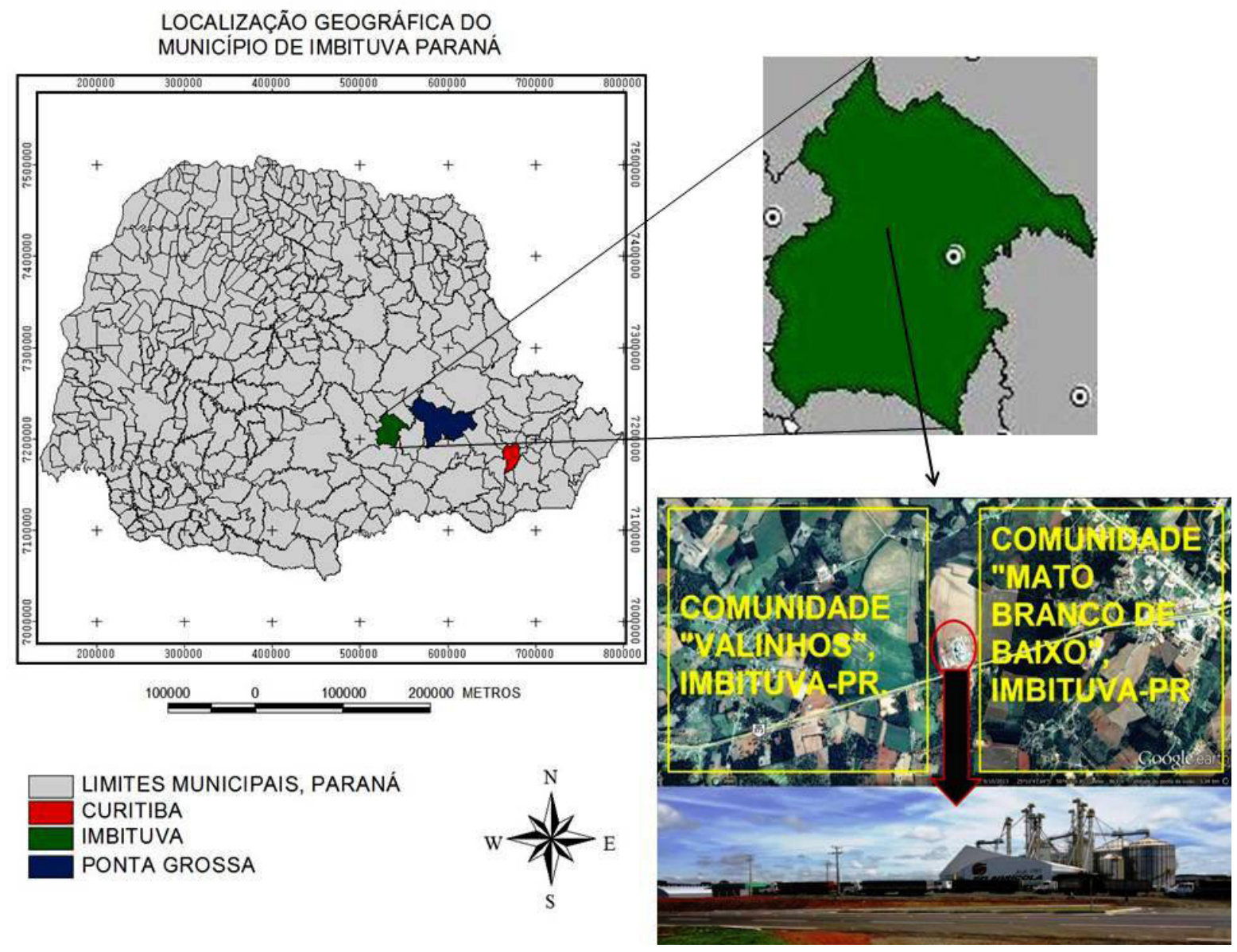

Fonte: os autores, 2013.

No ano de 2013 ocorreu a realização de entrevistas e aplicação de questionário. No que diz respeito às entrevistas, estas foram feitas com o responsável pelos trabalhos da unidade de comercialização e armazenamento no município. Também fez-se entrevistas atreladas ao questionário junto a 26 pessoas que moram no entorno da empresa, sendo 13 moradores da comunidade de Valinhos, e 13 moradores da comunidade de Mato Branco de Baixo.

Em entrevista com o gerente da unidade, perguntou-se quais motivos levaram a empresa Belagrícola a se fixar no município? Em resposta obteve-se: "O potencial da região. A oportunidade devido a pouca concorrência, assim como a necessidade dos produtores". Também 
foi perguntado: a BR 373 ou a estrutura agrícola do município propiciaram a instalação da empresa? Nas palavras do responsável: “Todas as unidades da empresa Belagrícola se encontram em ótimas localizações. No caso aqui de Imbituva o potencial agrícola do entorno (região) assim como a BR 373 foram determinantes".

A entrevista feita na empresa revelou a noção estratégica de uso do território. Como destacam Santos e Silveira (2012), cada empresa, cada ramo da produção, produz paralelamente uma lógica territorial, visível por meio do que se pode considerar uma topologia, isto é, a distribuição no território dos pontos de interesse para a operação dessa empresa, sendo o território um importante formador de pontos essenciais ao exercício das atividades de uma grande empresa. Elucida-se que a materialidade da infraestrutura rodoviária que abrange a área de fixação da empresa (Fig. 02), assim como os municípios produtores que ficam situados no entorno do território, e, que desta forma, não necessitarão pagar pedágio para levarem a produção até a unidade construída, foram fatores que possibilitaram a empresa se fixar no local, gerando assim, um uso racional do território.

\section{Figura 02 - Principais vias de transporte que passam pelo município}

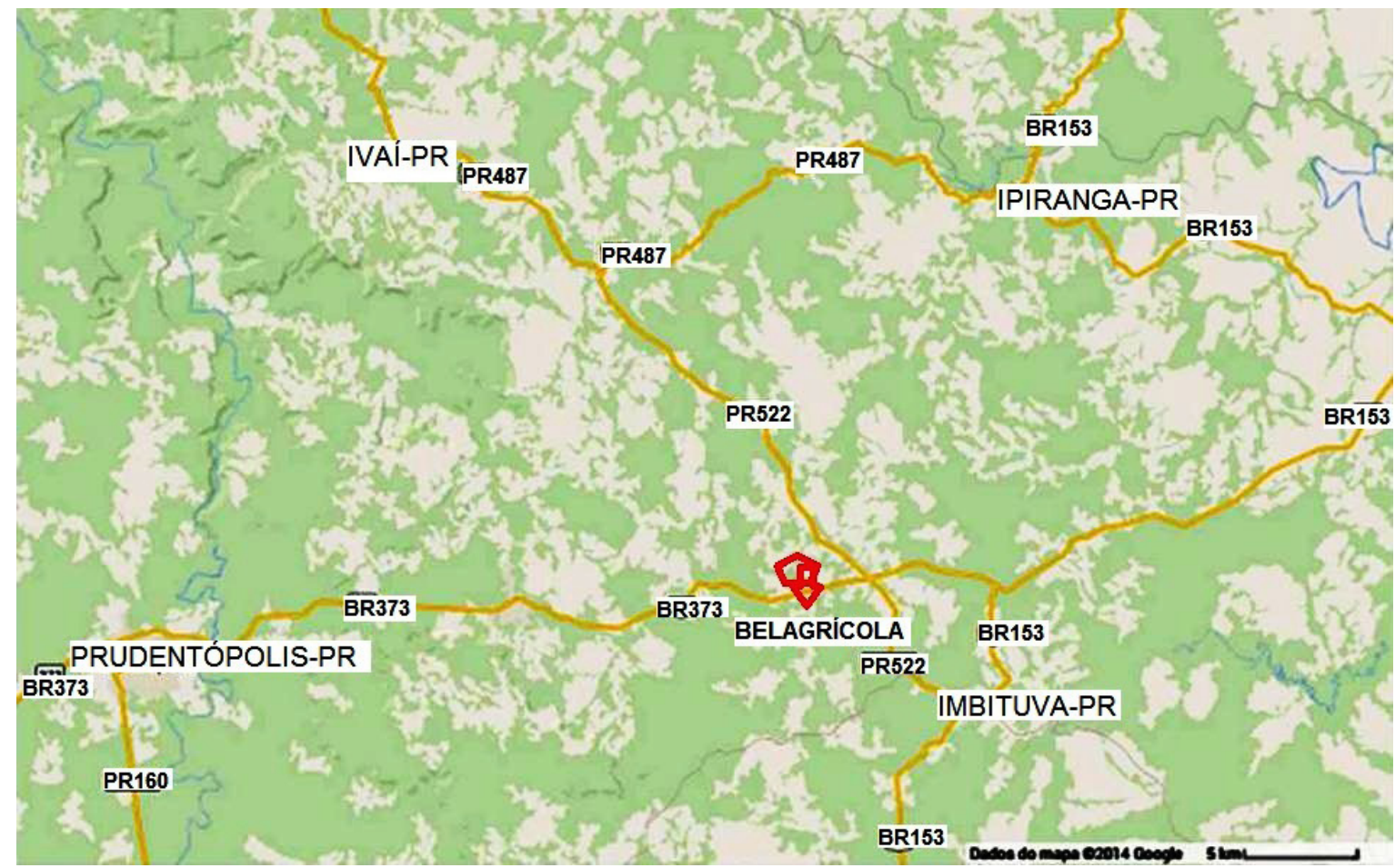

Fonte: Google Earth, 2013.

Também se perguntou: houve algum tipo de incentivo por parte do poder público municipal ou Estadual para a vinda e instalação da empresa? Quais? Em resposta o responsável afirma: "Não. Somos uma empresa privada, não necessitando deste tipo de coisa". Ao ser interrogado sobre os valores em reais destinados para a instalação da empresa no município, o gerente responsável ressaltou que foi direcionado um valor de 12 milhões de reais para a construção da unidade de armazenamento no território imbituvense. 
No que concerne ao número de empregos permanentes gerados na unidade de recebimento da empresa Belagrícola no município, bem como ao número de empregos temporários, obteve-se a seguinte resposta: "a empresa está gerando 13 empregos permanentes e irá gerar em torno de 20 empregos temporários".

Ao ser questionado sobre qual seria o foco da unidade instalada, ou seja, se seria apenas recebimento de grãos ou compra e venda, se obteve a seguinte fala: "Trabalhamos com o sistema Barter (troca de produtos por grãos). Esse sistema de troca é uma ferramenta a mais para o produtor. Nós financiamos o produtor, fornecemos insumos ... e logicamente fazemos um contrato, independente do tamanho da propriedade, da área plantada. Portanto, o produtor paga o financiamento com sua produção. O preço de entrega se dá no ato do contrato. Por exemplo: se o produtor necessitou de 20 mil para fazer o plantio, obviamente ele terá que pagar o valor que estará registrado no contrato e como uma ferramenta a mais de oportunidade, ele poderá entregar o valor que lhe fora financiado em grãos".

Perguntou-se também: existe uma quantia mínina de produção para que um produtor possa depositar na unidade ou vender para ela? Em resposta obteve-se: "Não, para nós não importa o tamanho da área. Desde que se produza e faça a troca, isso é independente para nós". No que tange à capacidade de armazenamento da unidade, de acordo com informações disponibilizadas pelo gerente, esta possui capacidade para estocar cerca de 600 mil sacas. Quanto à clientela da empresa, de acordo com informações prestadas pelo entrevistado "o maior número é de Imbituva, contudo recebemos também de municípios do entorno". Já a comercialização da produção adquirida pela Belagrícola no município imbituvense, esta se destina para empresas multinacionais como a Dreyfus, Bunge e Nidera.

Ao ser perguntado para o entrevistado quais as perspectivas futuras para a unidade de armazenamento presente no município, o mesmo responde: "Acredito que futuramente iremos industrializar determinados produtos na unidade mesmo". Por fim, perguntou-se se o mesmo acredita que a empresa poderá gerar o desenvolvimento das localidades ao seu entorno, e este respondeu da seguinte maneira: "Sim com certeza, gerando emprego e renda, assim como movimentando o mercado econômico do município. Por exemplo: a empresa tem carros (no momento seis) também possui alguns caminhões, e tudo isso gera um efeito nos postos de combustíveis no comércio, pois temos empregos sendo gerados. Também os caminhões, que são terceirizados. Enfim, movimenta-se a economia de diversas formas e isso contribui".

\section{O IMPACTO SOCIOECONÔMICO DA EMPRESA NO TERRITÓRIO E AS PERSPECTIVAS DOS MORADORES DAS DUAS COMUNIDADES VIZINHAS AS SUAS INSTALAÇÕES}

Quando a notícia da construção da empresa se espalhou pelas comunidades que ficam próximas a ela, alguns comentários surgiram. Cumpre ressaltar que o poder político responsável por gerir o município, já no ano de 2012 destacava nos meios de comunicação que: "uma empresa de grande porte estava sendo atraída para ser construída, e, que esta teria sua 
instalação em um terreno situado entre as comunidades de Valinhos e Mato Branco de Baixo, sendo que a empresa geraria desenvolvimento proporcionando emprego para muitas pessoas".

Em meio a essa disseminação que cunhava a ideia de desenvolvimento, muitas pessoas moradoras das duas comunidades criaram expectativas com a vinda da empresa. Estas persistem pois, em entrevista atrelada ao questionário que abordou os moradores de cada uma das comunidades localizadas no entorno da empresa, foi possível constatar que a grande maioria acredita que ela vai gerar um processo de desenvolvimento para ambas as comunidades (Quadro 04).

Quadro 04 - Entrevistas com moradores das comunidades de Valinhos e Mato Branco de Baixo, Imbituva-PR

continua

\begin{tabular}{|c|c|c|c|}
\hline Entre-vistado(a) & $\begin{array}{l}\text { Pergunta 01. Por que a empresa } \\
\text { Belagrícola foi construída } \\
\text { entre as duas comunidades } \\
\text { Valinhos/ Mato Branco? }\end{array}$ & $\begin{array}{l}\text { Pergunta } 02 \text {. Você irá } \\
\text { utilizar os serviços } \\
\text { prestadores pela } \\
\text { empresa? }\end{array}$ & $\begin{array}{l}\text { Pergunta 03. A empresa } \\
\text { Belagrícola vai gerar } \\
\text { desenvolvimento para sua } \\
\text { comunidade? Por quê? }\end{array}$ \\
\hline E1 & $\begin{array}{l}\text { Por ser bom para o povo abranger } \\
\text { as regiões produtoras. }\end{array}$ & Sim, comprando. & $\begin{array}{l}\text { Sim, gerando emprego facilitando o } \\
\text { comércio de produtos. }\end{array}$ \\
\hline E2 & $\begin{array}{l}\text { Pela proximidade da rodovia o } \\
\text { acesso e pelo terreno. }\end{array}$ & $\begin{array}{l}\text { Não, pois não trabalho } \\
\text { com isso. }\end{array}$ & $\begin{array}{l}\text { Sim, pelos empregos, pela } \\
\text { localização do secador. }\end{array}$ \\
\hline E3 & $\begin{array}{l}\text { Pela grandeza da região, por } \\
\text { possuir uma área de comércio. }\end{array}$ & Não. & $\begin{array}{l}\text { Sim, pela facilidade da venda } \\
\text { dos produtos, e pela geração de } \\
\text { empregos. }\end{array}$ \\
\hline $\mathrm{E} 4$ & $\begin{array}{l}\text { Por ter um espaço a disposição da } \\
\text { empresa. }\end{array}$ & $\begin{array}{l}\text { Sim, comprando e } \\
\text { vendendo. }\end{array}$ & $\begin{array}{l}\text { Sim sendo um local mais próximo } \\
\text { para os agricultores escoar a safra, } \\
\text { gerando empregos. }\end{array}$ \\
\hline E5 & Por causa do ponto de localização. & Sim, comprando. & $\begin{array}{l}\text { Sim, evoluindo e desenvolvendo a } \\
\text { localidade. }\end{array}$ \\
\hline E6 & $\begin{array}{l}\text { Por causa de estar entre as duas } \\
\text { praças de pedágio, ter bastante } \\
\text { produtores e por causa da rodovia. }\end{array}$ & Não. & Sim, gerando empregos na região. \\
\hline E7 & Localização e terreno. & Não. & $\begin{array}{l}\text { Sim, arrecadando impostos, por que } \\
\text { na verdade gera poucos empregos. }\end{array}$ \\
\hline E8 & $\begin{array}{l}\text { Bom para o lugar, gerando } \\
\text { emprego. }\end{array}$ & $\begin{array}{l}\text { Sim, comprando } \\
\text { insumos. }\end{array}$ & $\begin{array}{l}\text { Acredito que sim, gerando empregos } \\
\text { e concorrência entre outras } \\
\text { empresas. }\end{array}$ \\
\hline E9 & Não sei responder. & $\begin{array}{l}\text { Podendo comprar } \\
\text { produtos dela. }\end{array}$ & Não, pois gerou poucos empregos. \\
\hline E10 & $\begin{array}{l}\text { Proximidade da rodovia, ponto } \\
\text { bom. }\end{array}$ & $\begin{array}{l}\text { Sim, comprando } \\
\text { produtos. }\end{array}$ & Sim, gerando empregos. \\
\hline E11 & Para gerar empregos. & $\begin{array}{l}\text { Não, pois não trabalho } \\
\text { no ramo. }\end{array}$ & $\begin{array}{l}\text { Sim gerando empregos para os } \\
\text { empregados. }\end{array}$ \\
\hline E12 & Não sei informar. & $\begin{array}{l}\text { Sim, podendo comprar } \\
\text { produtos. }\end{array}$ & Sim, gerando empregos. \\
\hline E13 & Não tenho ideia. & Não sei. & Não sei. \\
\hline E14 & Não sei informar. & Não. & Não. \\
\hline
\end{tabular}


Quadro 04 - Entrevistas com moradores das comunidades de Valinhos e Mato Branco de Baixo, Imbituva-PR

conclusão

\begin{tabular}{|c|c|c|c|}
\hline Entre-vistado(a) & $\begin{array}{l}\text { Pergunta } 01 \text {. Por que a empresa } \\
\text { Belagrícola foi construída } \\
\text { entre as duas comunidades } \\
\text { Valinhos/ Mato Branco? }\end{array}$ & $\begin{array}{l}\text { Pergunta } 02 \text {. Você irá } \\
\text { utilizar os serviços } \\
\text { prestadores pela } \\
\text { empresa? }\end{array}$ & $\begin{array}{l}\text { Pergunta 03. A empresa } \\
\text { Belagrícola vai gerar } \\
\text { desenvolvimento para sua } \\
\text { comunidade? Por quê? }\end{array}$ \\
\hline E15 & $\begin{array}{l}\text { Por ser um lugar bom, ficou um } \\
\text { lugar bem instalado e para gerar } \\
\text { empregos. }\end{array}$ & Não sei. & Sim, gerando empregos. \\
\hline E16 & Não sei responder. & Não. & Sim, gerando empregos. \\
\hline E17 & $\begin{array}{l}\text { Para gerar empregos, para a } \\
\text { população e por ser um espaço } \\
\text { bom. }\end{array}$ & $\begin{array}{l}\text { Sim, comprando } \\
\text { produtos. }\end{array}$ & $\begin{array}{l}\text { Sim, comprando produtos locaise } \\
\text { trazendo muitos produtores para } \\
\text { vender para empresa. }\end{array}$ \\
\hline E18 & $\begin{array}{l}\text { Para gerar empregos para bastante } \\
\text { gente. }\end{array}$ & Sim, poderia comprar. & Sim, mas não sei explicar. \\
\hline E19 & Por causa da rodovia. & Não. & $\begin{array}{l}\text { Sim, gerando empregos e } \\
\text { influenciando outras empresas a se } \\
\text { fixarem na localidade. }\end{array}$ \\
\hline E20 & $\begin{array}{l}\text { Por causa da proximidade da } \\
\text { rodovia. }\end{array}$ & $\begin{array}{l}\text { Sim, comprando } \\
\text { insumos agrícolas. }\end{array}$ & $\begin{array}{l}\text { Indiferente, pois não gera muitos } \\
\text { empregos. }\end{array}$ \\
\hline E21 & Não sei informar. & $\begin{array}{l}\text { Pretendo, mas no } \\
\text { momento não sei de que } \\
\text { forma. }\end{array}$ & $\begin{array}{l}\text { Sim, gerando um aumento no } \\
\text { comércio local. }\end{array}$ \\
\hline E22 & $\begin{array}{l}\text { Porque o lugar era bom, para gerar } \\
\text { empregos. }\end{array}$ & Vender vai ser difícil. & $\begin{array}{l}\text { Vai desenvolver gerando mais } \\
\text { empregos. }\end{array}$ \\
\hline E23 & $\begin{array}{l}\text { Por causa da localização, para } \\
\text { gerar empregos. }\end{array}$ & Sim. & Sim. \\
\hline E24 & $\begin{array}{l}\text { Para gerar emprego e para as } \\
\text { pessoas que produzem. }\end{array}$ & $\begin{array}{l}\text { Não, mais meu marido } \\
\text { trabalha lá. }\end{array}$ & Sim, por ser uma firma grande. \\
\hline E25 & Não tenho conhecimento. & Não. & $\begin{array}{l}\text { Vai gerar desenvolvimento para as } \\
\text { pessoas que produzem. }\end{array}$ \\
\hline E26 & $\begin{array}{l}\text { Por causa do comércio e por causa } \\
\text { das pessoas para trabalhar na } \\
\text { empresa. }\end{array}$ & $\begin{array}{l}\text { Sim, comprando } \\
\text { produtos dela. }\end{array}$ & Sim, gerando empregos. \\
\hline
\end{tabular}

Fonte: os autores, 2013.

Ao analisar as respostas obtidas, percebe-se que 12 pessoas mencionam que a empresa se instalou devido ao local ser estratégico. Chama a atenção que já na primeira pergunta várias pessoas associam a construção da unidade de recebimento de grãos à questão de emprego. Outro fato interessante que se constata ao serem analisadas as repostas obtidas da segunda questão, é que 13 pessoas disseram que irão utilizar dos serviços que estão sendo prestados pela empresa, contudo, destaca-se que dessas 13 pessoas, apenas uma manifestou que irá comprar e também vender, ou seja, as outras irão apenas comprar os produtos ofertados (que ainda não existem, uma vez que a produção atual se direciona à multinacionais). 
Percebe-se, conversando com essas pessoas, que a maioria é agricultor familiar, possuindo pouca área para cultivar, sendo que muitos cultivam fumo e já compram insumos agrícolas da empresa. Ainda com relação a essa segunda pergunta, constata-se que 11 pessoas afirmaram que não pretendem utilizar os serviços prestados pela empresa, e duas ainda não sabem. Porém, no caso das 11 pessoas que afirmaram que não irão utilizar os serviços prestados pela empresa, dez delas mesmo assim acreditam que a Belagrícola irá gerar desenvolvimento por meio de empregos em seu entorno. Apenas uma pessoa destacou que foi pequeno o número de empregos gerados mas, mesmo assim, acredita no desenvolvimento pela via de impostos recolhidos no município.

No que tange a terceira pergunta, é possível ver que 21 dizem acreditar que a empresa irá gerar desenvolvimento para as comunidades do entorno, bem como para o município. É interessante que essas respostas mencionam o emprego, pois como foi abordado anteriormente, essa empresa foi construída no município a partir de discursos políticos que a relacionam à geração de elevado número de empregos, fato que na realidade não ocorreu até o momento, já que a empresa contratou somente 13 pessoas em caráter permanente. Três pessoas responderam acreditar que a empresa não irá gerar desenvolvimento, inclusive a resposta do entrevistado E20 aponta o seguinte: "Indiferente, pois não gera muitos empregos". Duas pessoas não souberam responder.

É impressionante perceber a confiança depositada pelas pessoas no sentido do "desenvolvimento que a empresa irá gerar", no entanto, como se pode perceber na fala do responsável pela Belagrícola no município, conclui-se que pela via de empregos dificilmente a população local irá presenciar um processo de desenvolvimento.

Torna-se importante retomar os dados apresentados no Quadro 01 pois, como se observou, o município de Imbituva possui 1.632 propriedades menores que 20ha, perfazendo $78 \%$ do total dos estabelecimentos contidos no censo agropecuário de $2006^{2}$. Portanto, a empresa Belagrícola tem um impacto positivo para um pequeno número de produtores - potencialmente os $22 \%$ que possuem mais de 20 ha disponíveis para plantio). Sendo assim, em poucos estabelecimentos seria possível haver o plantio de soja e milho para comercialização.

Mas, como ficou claro na entrevista feita com o responsável pela empresa, esta estabelece um uso do território, na medida em que aproveita além da materialidade das rodovias, a estrutura agrícola do município. Apesar de ser pouco o número de estabelecimentos agrícolas com maior quantidade de área, estes abarcam no total o maior número de área em hectares, permitindo assim servirem aos interesses da empresa no território imbituvense. Em síntese é possível afirmar que de fato o território municipal ofereceu à empresa condições para a sua instalação e consequente uso.

2 Destaca-se que se está utilizando para este estudo dados do ano de 2006 devido a dificuldade de obter dados do IBGE do último censo realizado em 2010. 


\section{CONSIDERAÇÕES FINAIS}

Os estudos que permitiram a realização deste artigo possibilitaram compreender que a empresa Belagrícola estabeleceu um uso consciente do território. Compreendeu-se por meio dos dados coletados que os principais fatores que influenciaram a fixação da empresa no município foram localização geográfica, economia e malha rodoviária. Tais fatores permitiram a existência de uma dinâmica favorável para a fixação da empresa.

No que tange as expectativas da população vizinha em relação à instalação da empresa, foi possível perceber que a disseminação de discursos políticos que enfatizavam a vinda de uma grande empresa que iria desenvolver o município foram predominantes na formação de uma imagem positiva da Belagrícola. Entretanto, a atuação da mesma não tem respaldado as expectativas criadas no pensar da maioria dos habitantes de seu entorno.

Aponta-se que, ao se considerar a estrutura econômica do município, percebeu-se que a fixação da Belagrícola no território de Imbituva irá beneficiar uma pequena parcela de produtores rurais. Assim sendo, compreendeu-se que a grande maioria dos estabelecimentos não são os que de fato usufruirão dos serviços prestados pela empresa, que se fixou no imaginário de muitas pessoas como a empresa que geraria desenvolvimento para o território.

\section{REFERÊNCIAS}

ANDRADE, Manuel Correia. A questão do território no Brasil. São Paulo: HUCITEC, 1995.

BELAGRÍCOLA. Nossa empresa. 2013. Disponível em: <http:/ / www.belagricola.com.br/nossa-empresa/ quem-somos> Acesso em: 10 out. 2013.

BOBATO, Zaqueu Luiz. O impacto socioeconômico gerado pela fumicultura na microrregião geográfica de Prudentópolis-PR. Geosul, Florianópolis, v. 28, n. 55, p 31-54, 2013.

COSTA, Jodival Maurício; UEDA, Vanda. Redes técnicas e território: notas sobre a reticulação espacial. BGG, n. 32, p. 131-145, 2007.

COSTA, Jodival Maurício da. Redes técnicas e uso privado do território na Amazônia: o caso da Estrada de Ferro Carajás da Companhia Vale do Rio Doce (1997-2006). Porto Alegre, 2008. 116 f. Dissertação (Mestrado em Geografia) - Universidade Federal do Rio Grande do Sul. Disponível em: <http:/ / www.lume.ufrgs.br/ bitstream/handle/10183/13549/000648223.pdf?sequence=1>. Acesso em: 12 ago. 2013.

CORREAA, Roberto Lobato. Trajetórias geográficas. Rio de Janeiro: Bertrand, 2001. p. 107- 118.

HAESBAERT, Rogério. O mito da desterritorialização: do "fim dos territórios" à multi-territorialidade. Rio de Janeiro: Bertrand Brasil, 2011.

IBGE. Instituto Brasileiro de Geografia e Estatística. Histórico, 2013a. Disponível em: < http:/ / cidades.ibge. gov.br/painel/historico.php?lang=\&codmun=411010\&search=parana | imbituva $\mid$ infograficos:-historico $>$. Acesso em: 15 abr. 2013.

Imbituva, 2013b. Disponível em: <http:/ / cidades.ibge.gov.br/xtras/perfil.php?lang=\&codmun=4 11010\&search=parana $\mid$ imbituva $>$. Acesso em: 15 out. 2013.

Censo Demográfico ano 2010: sinopse. Disponível em: <http://cidades.ibge.gov.br/xtras/temas. php?lang=\&codmun=411010\&idtema=1\&search=parana $\mid$ imbituva $\mid$ censo-demografico-2010:-sinopse-> . Acesso em: 15 out. 2013. 
IPARDES. Instituto Paranaense de Desenvolvimento Econômico e Social. Arranjo produtivo local de instrumentos, equipamentos e aparelhos médico-odonto-hospitalares da Microrregião de Curitiba. Estudo de caso: versão preliminar. Curitiba, 2006.

Caderno estatístico município de Imbituva. Setembro de 2013. Disponível em: <http://www. ipardes.gov.br/cadernos/Montapdf.php?Municipio=84430\&btOk=ok>. Acesso em: 10 out. 2013.

Relação dos municípios do estado ordenados segundo as mesorregiões e as microrregiões geográficas do IBGE. Curitiba, 2012.

MINEROPAR. Minerais do Paraná S.A. Projeto riquezas minerais: avaliação do potencial mineral e consultoria técnica no Município de Imbituva. Relatório final. Curitiba, Outubro de 2002. Disponível em: <http://www.mineropar.pr.gov.br/arquivos/File/publicacoes/relatorios_concluidos/44_relatorios_ concluidos.PDF>. Acesso em: 10 jun. 2011.

MORAES, Antônio Carlos Robert. Geografia: pequena história crítica. São Paulo, HUCITEC, 1996.

PEREIRA, Mirlei Frachini Vicente; KAHIL, Samira Peduti. O território e as redes: considerações a partir de estratégias de grandes empresas. In: GERARDI, Lucia Helena de Oliveira; CARVALHO, Pompeu Figueiredo de (Orgs). Geografia: ações e reflexões. Rio Claro: UNESP/ Associação de Geografia Teorética - AGETEO, 2006. p. 217-219.

PREFEITURA Municipal de Imbituva. Economia imbituvense, 2013. Disponível em: <http://www. imbituva.pr.gov.br/index.php/municipio/dados-do-municipio/economia-imbituvense>. Acesso em: 10 out. 2013.

RAFFESTIN, Claude. Por uma geografia do poder. São Paulo: Ática, 1993.

SANTOS, Milton; SILVEIRA, Maria Laura. O Brasil: território e sociedade no início do século XXI. 16. ed. Rio de Janeiro: Record, 2012.

SANTOS, Milton et al. Território, territórios: ensaios sobre o ordenamento territorial. 2.ed. Rio de Janeiro: AP\&A, 2006. p. 13-23.

SANTOS, Milton. A Natureza do Espaço: técnica e tempo, razão e emoção. São Paulo: HUCITEC, 1996.

SAQUET, Marcos. Os tempos e os territórios da colonização italiana. Porto Alegre: EST Edições, 2003. 